\title{
A POTENNCIA DA CRÍTICA: O PROBLEMA DA APORIA EM HABERMAS E SEU DESTINO EM ADORNO
}

\author{
Leomir Cardoso Hilário* \\ leomirhilario@yahoo.com.br
}

RESUMO Este artigo procura refletir acerca do ponto a partir do qual Habermas afirma a inatualidade da crítica social da primeira geração frankfurtiana, em especifico Adorno, a saber, a ideia de que a crítica radical da racionalidade articulada com a análise social conduziria inevitavelmente a uma aporia analítica, a qual só poderia ser superada pela mudança de paradigma no interior da teoria crítica. Focalizando como Adorno busca manter a situação aporética da crítica social, busco redimensionar a aporia tirando-a do registro de obstáculo inultrapassável em direção à condição de possibilidade do exercício crítico.

Palavras-chave Adorno, aporia, Escola de Frankfurt, Teoria Crítica, Habermas.

ABSTRACT This article seeks to reflect on the point from which Habermas argues on the obsolescence of social criticism of the first generation from the Frankfurt School, especially Adorno, from the idea that the radical critique of rationality articulated with social analysis would inevitably lead to an analytic aporia, which could only be overcome by the paradigm shift within the critical theory. Focusing as Adorno tries to keep the aporetic situation of social critique, we sought to re-dimension the idea of the obstacle of aporia

* Doutorando em Psicologia Social (PPGPS-UERJ). Artigo recebido em 07/01/2013 e aprovado em 15/06/2013.

KRITERION, Belo Horizonte, nº 129, Jun./2014, p. 309-329 
by removing it from the unsurpassable obstacle towards the condition of possibility of the critical exercise.

Keywords Adorno, aporia, Critical Theory, Frankfurt School, Habermas.

[...] o paradoxo é a paixão do pensamento, e o pensador sem um paradoxo é como o amante sem paixão, um tipo medíocre. Mas a potência mais alta de qualquer paixão é sempre querer a sua ruína, e assim também a mais alta paixão da inteligência consiste em querer o choque não obstante o choque de uma ou outra maneira tenha de tornarse a sua ruína. Assim, o maior paradoxo do pensamento é querer descobrir algo que ele próprio não possa pensar. (Kierkegaard, 1995, pp. 61-62)

O pensamento frankfurtiano da primeira geração, notadamente Adorno e Horkheimer, procede com radicalidade no que diz respeito à análise social. Em "A Dialética do Esclarecimento", tal radicalidade guia a leitura da história que não está necessariamente ligada ao progresso humano, mas, ao contrário, à catástrofe, tal qual o "Angelus Novus" de Klee lido por Benjamin (1991). Também a própria racionalidade ou o pensamento não escapam, pois são postos em tela de juízo e perdem sua imunidade diante dos efeitos de barbárie. Em uma palavra, já não haveria como vislumbrar possibilidades emancipatórias historicamente capazes de superar o presente. Embora a necessidade da crítica e da negatividade continuasse a existir.

A primeira frase da introdução à "Dialética negativa" diz respeito a esta problemática: "A filosofia, que um dia pareceu ultrapassada, mantémse viva porque se perdeu o instante de sua realização" (Adorno, 2009, p. 7). Ao mesmo tempo que a realização da filosofia se torna imprescindível, ela se demonstra impossível. Por meio destas palavras, Adorno parece colocarse diante da necessidade de pensar depois do que se imaginava ser o tempo da realização da filosofia, quer dizer, num mundo onde a técnica e as forças produtivas avançaram significativamente sem que isso tenha implicado uma modificação social em direção à sociedade não capitalista. A perspectiva de Adorno, como defende Nobre (1998, p. 157), "não é a de uma emancipação por vir, mas a de uma emancipação que não se deu e continua a não se dar".

Durante a segunda metade do século XX, a recepção de tal procedimento analítico foi balizada pela leitura segundo a qual tais autores seriam demasiadamente pessimistas ou perigosamente radicais, entre outros demais rótulos cujo objetivo foi demarcar suas limitações de análise. E foi sobretudo no interior da própria tradição da teoria crítica que vieram avaliações duras. A exemplo, a chamada "segunda geração frankfurtiana", em especial Habermas, 
fez da crítica a tal procedimento um dos pontos de partida para sua elaboração teórica e filosófica.

De acordo com Rouanet (1987), o conceito de racionalidade de dupla face, isto é, instrumental e comunicativa, permite que Habermas resolva as seguintes aporias da crítica de Adorno: primeira aquela de uma razão que continua exercendo sua atividade, mesmo depois de ter perdido todo direito à existência devido ao seu entrelaçamento com a dominação; segunda aquela que, na esteira de Nietzsche, realiza uma crítica total da razão que compromete seus próprios fundamentos, pois utiliza as armas da razão para denunciar a razão; e terceira a que se refere à necessidade de o conceito ultrapassar o próprio conceito, isto é, afirmar a não identidade por meio de um procedimento cuja lei de funcionamento é justamente subsumir o não idêntico na unidade do idêntico. Isso torna possível a Habermas, entre outros ganhos, salvar o fundamento que permite o exercício crítico: já que é uma forma de racionalidade, a comunicativa, que permite realizar a crítica.

O objetivo deste artigo não é discutir profundamente a arquitetura desta crítica habermasiana, mas sim esboçar os contornos gerais dela, focalizando a questão da aporia ou da situação aporética da crítica de Adorno e Horkheimer em relação à racionalidade para, em seguida, problematizá-la a partir do entendimento que estes tinham de tal situação. ${ }^{1}$ Por isso, trata-se de refletir acerca de qual é o papel assumido pela aporia na primeira geração frankfurtiana. Porque, se, por um lado, em Habermas a aporia é índice de superação do procedimento de crítica radical à racionalidade, por outro, em Adorno e Horkheimer trata-se não de um destino ao qual a crítica seria conduzida, mas de um ponto de partida a ser mantido em seu procedimento. Esta discussão tem sua relevância não apenas para o interior da Escola de Frankfurt, mas também para as possibilidades analíticas de uma crítica radical da racionalidade, da modernidade e do capitalismo, isto é, para aquilo que aqui se chama de potência da crítica.

Convém estabelecer os significados etimológico e filosófico de aporia, à guisa de introdução ao conceito e suas problemáticas. Segundo o "Grande Dicionário Houaiss de Língua Portuguesa”, há quatro acepções desse termo: a primeira refere-se à dificuldade ou dúvida racional decorrente da

1 Devido ao escopo do artigo e ao espaço diminuto desta escrita, decidi não investigar diretamente o giro linguístico operado por Habermas, consciente do ônus que essa decisão pode ocasionar. Desta maneira, passo apenas tangencialmente por este giro e foco a reflexão sobretudo no que fundamenta a exigência de superação da crítica empreendida pela primeira geração frankfurtiana, por meio da noção de aporia. Apesar disso, indico dois livros de Habermas (1990; 2004) para uma leitura mais específica dos desdobramentos deste problema no que se refere ao pensamento habermasiano. 
impossibilidade objetiva na obtenção de uma resposta ou conclusão para determinada indagação filosófica; a segunda, tomando como base as ideias de Aristóteles, seria um problema lógico, contradição, paradoxo nascido da existência de raciocínios igualmente coerentes e plausíveis que alcançam conclusões contrárias; a terceira significando situação insolúvel, sem saída; e a quarta, referindo-se às aporias do filósofo pré-socrático Zenão de Eléia, as quais tinham por objetivo provar que as ideias de multiplicidade e movimento conduzem o pensamento a impasses e contradições lógicas insuperáveis.

Etimologicamente, aporia é palavra composta do prefixo negativo $a$ - e pelo substantivo póros (passagem, via de comunicação, caminho, trajeto). Póros pertence a uma família de palavras como poreúo, que significa fazer passar, transportar, conduzir a algum lugar, realizar um trajeto; e porízo: abrir caminho, encontrar passagem, dar passagem a, transmitir. Por extensão, significam chegar a uma conclusão, deduzir, inferir. Aporia significa: incapacidade de encontrar caminho ou trajeto; falta de uma via ou um meio de passagem; impossibilidade de chegar a algum lugar; por extensão, impossibilidade de deduzir, concluir, inferir. A aporia é uma dificuldade insolúvel (Chauí, 2002, p. 495).

De acordo com Abbagnano (2012, p. 84), em seu "Dicionário de Filosofia", esse termo é usado no sentido de dúvida racional, de dificuldade inerente a um raciocínio, e não do estado subjetivo de incerteza. É, portanto, a dúvida objetiva, a dificuldade de um raciocínio ou da conclusão a que leva um raciocínio. Em Japiassu e Marcondes (2006), aporia diz respeito, por um lado, à dificuldade lógica insuperável num raciocínio, denotando especificamente tudo o que faz com que um pensamento não possa avançar e, por outro, ao que não tem solução, como no exemplo dos diálogos socráticos de Platão que terminam sem uma solução definitiva para a questão examinada, valorizando mais o exame do problema do que sua solução final. Esta última definição é sobejamente importante na medida em que sinaliza para a duplicidade própria da aporia, a qual procuraremos defender: tanto como limitação lógica e obstáculo ao pensamento quanto exame do problema que deixa em suspenso a solução.

No "Le vocabulaire de l'ecole de Francfort", o verbete aporia não existe. Apesar disso, defendemos que este termo é demasiadamente marcante na economia discursiva da segunda geração frankfurtiana, em especial Habermas e sua avaliação de como a primeira teoria crítica se enreda em contradições insolúveis, determinando assim a mudança de paradigma necessária para a racionalidade comunicativa. 
Deste modo, esta noção me é central porque é mediante o entendimento da aporia como índice de inevitabilidade da mudança de paradigma no interior da tradição da teoria crítica - ou seja, a leitura habermasiana segundo a qual o pensamento da primeira geração frankfurtiana, em especial Adorno, enreda-se em dificuldades insuperáveis e, portanto, necessita de uma correção no que se refere à crítica da razão - que buscaremos reposicionar a aporia avaliando o destino que lhe é dado por Adorno.

Resgatar a aporia de outra forma que não se referindo aos obstáculos inultrapassáveis ou dificuldades insuperáveis permite reafirmar a potência da crítica, é esta a tarefa deste artigo. Se, como defende Jay (2003a), a teoria crítica é composta sobretudo por específico campo de forças, talvez a aporia ocupe nele papel fundamental. Ou seja, a manutenção da condição aporética da crítica garante efetivamente aquilo a que ela se propõe no que concerne aos efeitos de análise radical do presente. A aporia, em uma palavra, é a virtude da crítica radical e não seu obstáculo ou impedimento.

\section{O problema da aporia em Habermas}

Segundo Habermas, o pensamento frankfurtiano da primeira geração se encontraria diante de dificuldades insolúveis, as quais sinalizariam para sua inevitável superação. Numa palestra proferida na Sociedade Coreana de Filosofia, em maio de 1996, Habermas reflete acerca de duas tradições que leem a modernidade de diferentes maneiras:

Isso dirige a nossa atenção para o conceito clássico de modernidade tal como ele foi inicialmente determinado por Hegel e desdobrado, com base na teoria da sociedade, por Marx, Max Weber, pelo primeiro Lukács e pela primeira Escola de Frankfurt. Essa tradição enredou-se finalmente de modo aporético na auto-referencialidade de uma crítica totalizante da razão. Daí por que o projeto de uma certificação autocrítica da modernidade foi continuado com a ajuda de um outro conceito da razão - o de uma razão personificada e "situada" linguisticamente (Habermas, 2001, p. 167).

A partir destas palavras, podemos entender quais são os elementos em jogo: um diagnóstico da modernidade, a crítica da razão e a necessidade de outro modelo de racionalidade. Para Habermas, a noção weberiana de racionalização da sociedade está comprometida com a questão da dialética do Esclarecimento. ${ }^{2}$ Deste modo, pode-se ver em que medida esse diagnóstico de

2 Quando a referência é feita à obra de Adorno e Horkheimer, utilizo a mesma expressão entre aspas. No entanto, quando se quer mencionar o período histórico que é objeto de investigação de ambos os autores, utilizo a expressão em itálico. 
época conduz a uma "rua sem saída observando-se as consequências aporéticas da Teoria Crítica mais antiga que, sob as premissas do marxismo ocidental, deu continuidade ao programa de pesquisa de Max Weber" (Habermas, 2001, p. 176).

Habermas (2010) retoma nessa pequena conferência, de modo resumido, parte de seus argumentos de sua obra, "Teoria da ação comunicativa", sobretudo no que se refere ao primeiro tomo da obra dedicado à racionalidade da ação e da racionalização social, onde ele busca analisar como, de Lukács a Adorno, as formulações de Weber se inscrevem para fundamentar a análise da racionalização como coisificação sob o título de crítica da razão instrumental. Especificamente o capítulo IV, intitulado "De Lukács a Adorno: racionalização como reificação", onde se enfatiza a inscrição de Weber na tradição do marxismo ocidental e a problemática da crítica da razão instrumental.

Voltando à conferência citada anteriormente, Habermas (2001, p. 180) defende que a "Dialética do Esclarecimento" pode ser compreendida como a "retro-tradução das teses weberianas na linguagem da filosofia da história hegeliano-marxista". Entende, também, que o diagnóstico da modernidade oriundo de Max Weber acaba por desenvolver um "quadro-negro de uma sociedade administrada", uma vez que se observa, por toda parte, uma conversão de liberdades em disciplinas, de aparentes progressos em, na verdade, continuação e complexificação de processos de poder.

O objetivo dessa crítica de Habermas, compartilhada por Honneth (2009), membro da terceira geração frankfurtiana, ${ }^{3}$ é mostrar como os traços ambivalentes da modernidade são apagados e, em seu lugar, é posta a imagem de uma modernidade totalitária, unidimensional:

A dialética hegeliana do Esclarecimento teve sua ponta quebrada. Pior ainda, à medida que a racionalidade instrumental incha e torna-se um todo irracional, a crítica do todo falso enreda-se em uma aporia. Assim que a crítica da razão instrumental não pode mais ser realizada em nome da razão, ela - e com ela a crítica da modernidade - perde um fundamento normativo próprio. Adorno fez da dificuldade aporética a qual como que é tornada consciente na execução da crítica auto-referencial - a virtude da dialética negativa. Ele permaneceu fiel ao empreendimento de uma crítica declaradamente paradoxal e "sem chão", à medida que desmentiu exatamente as condições que deveriam ser preenchidas para que fosse possível a operação da crítica realizada in actu (Habermas, 2001, pp. 180-181).

3 Investigo o pensamento de Honneth, no que tange ao período inicial de suas formulações, ao modo como ele compreende a história da teoria crítica e sua avaliação acerca de Adorno, Horkheimer e Foucault, no artigo intitulado "Michel Foucault e a Escola de Frankfurt: reflexões a partir da obra Crítica do Poder" (Honneth, 2012). 
Ao entender o processo da modernidade desprovido de qualquer ambivalência, sendo quase que univocamente moldado por processos de dominação, o próprio gesto de crítica se encontraria danificado em Adorno. Ou seja, ao radicalizar a crítica da razão e afirmar seu conluio com a dominação, perder-se-ia o próprio fundamento que permite realizar tal crítica, pois a Razão encontrar-se-ia em situação suspeita, ela própria sub judice. Ao radicalizar-se, portanto, a crítica não teria outro caminho senão dirigir-se a um beco sem saída, sem conseguir fundamentar, por exemplo, por que e como esta crítica consegue se desvencilhar, de alguma maneira, da própria dialética do Esclarecimento.

Habermas pontua, mais de uma vez, que Adorno está devidamente cônscio do enredamento aporético no qual seu pensamento se encontrava. $\mathrm{Na}$ conferência de 1996, como vimos, por exemplo, ele afirmou que Adorno $f e z d a$ dificuldade aporética a virtude da dialética negativa. Porém: como Adorno foi capaz de transformar algo ao qual sua crítica seria necessariamente conduzida, isto é, um beco sem saída, em virtude de seu próprio empreendimento?

Habermas afirma, por exemplo, mais de uma década antes de sua conferência, em seu "Discurso Filosófico da Modernidade", como a crítica empreendida por Adorno

denuncia o Esclarecimento que se tornou totalitário com os meios do próprio Esclarecimento. Adorno estava perfeitamente consciente dessa contradição performativa da crítica totalizada. A Dialética Negativa, de Adorno, pode ser lida como a continuação da explicação de por que temos que girar em torno dessa contradição performativa, e devemos persistir nela. [...] Durante os vinte e cinco anos após a conclusão da Dialética do Esclarecimento, Adorno permaneceu fiel ao impulso filosófico, sem se furtar à estrutura paradoxal de um pensamento da crítica totalizada (Habermas, 2000, p. 170).

De acordo com Jay (2003b, p. 63), a contradição performativa não surge quando se afirmam simultaneamente como verdadeiras duas proposições antitéticas, mas sim quando qualquer coisa que se declare está em desacordo com os supostos ou implicações do ato de fala. Em outras palavras, a contradição performativa se produz quando a dimensão locucionária de um ato de fala está em conflito com sua força ilocucionária, quando o que se diz perde impacto pela maneira como se diz. Para Habermas, o uso comunicativo da linguagem esconde uma obrigação imanente de justificar as pretensões de validade. Quando as declarações que são feitas em um nível locucionário negam a possibilidade mesma de tal justificação, incorre-se em uma contradição performativa. 
Portanto, este contrassenso emerge quando há contradição entre a pretensão de validade de verdade (conteúdo ilocucionário) com o conteúdo proposicional (locucionário). Repa (2008, p. 295) dá o seguinte exemplo ilustrativo: suponhamos que alguém afirme que não existe nenhuma verdade. Nesta afirmação, há uma reivindicação àquilo que a própria sentença procura negar: para que não exista verdade é necessário que a verdade de que não há verdade seja procedente. Contradizem-se a proposição e os pressupostos pragmáticos do ato de fala que incorpora a proposição.

A ideia de contradição performativa se apresenta como forma de Habermas discutir as críticas da razão de Adorno e dos pós-estruturalistas, uma vez que, se estes argumentam, em linhas gerais, que a razão é dominação, apoiam-se no pressuposto de que seu argumento, de algum modo, é racional e livre desse jogo. A solução encontrada por Habermas, para realizar a crítica da modernidade e da racionalidade instrumental, foi apoiar-se num conceito complexo e amplo de razão, livrando-se, assim, da contradição performativa. É por meio desta via linguística que Habermas compreende a aporia em Adorno e toma como necessária sua superação.

Resta investigar, a partir de então, não tanto por que Adorno preferiu não ceder à aporia em nome de uma outra racionalidade que ancorasse a sua crítica, mas como foi possível que ele não cedesse às dificuldades insolúveis de seu procedimento, embora estivesse plenamente ciente delas. Minha hipótese é a de que reposicionando ou ressignificando a aporia se torna possível sustentar a viabilidade das reflexões frankfurtianas no que diz respeito à crítica radical da racionalidade. De modo que a aporia não seja tanto aquilo ao qual a crítica é conduzida, isto é, não seja uma consequência do procedimento, mas sim seu ponto de partida. Se Habermas estiver certo ao defender que Adorno tinha mesmo consciência da situação aporética de seu pensamento, vale a pena investigar como é que ele se dirige a esta questão e como a entende.

Em Habermas está em jogo o modo como a primeira geração frankfurtiana, em especial Adorno, não conseguiria encontrar ponto de escape à própria forma como entende a racionalidade: questiona-se o modo pelo qual se pode sustentar uma crítica da razão ao mesmo tempo que se afirma que é a própria razão que está na raiz da regressão reinante no mundo administrado.

É uma forma de compreender esta situação aporética com base no registro da superação de seus obstáculos mediante o abandono da crítica radical à racionalidade e à modernidade. O problema é o de como Adorno e Horkheimer perderiam de vista a dialética: questiona-se esta perda referida a uma ambivalência dos processos da modernidade, já que o germe destrutivo se encontra no seio do projeto emancipatório iluminista. Assim, a dialética do 
Esclarecimento acaba por se converter não tanto numa dialética, ou seja, num embate entre forças, mas num processo onde a barbárie se intensifica a ponto de converter a razão em mero instrumento de poder e dominação.

Por meio desta forma de compreensão, qual seja, de que a crítica social da primeira geração frankfurtiana se enredaria em contradições insolúveis com relação à crítica da razão, buscarei refletir acerca de qual é o papel exercido pela aporia no interior do pensamento social da primeira geração frankfurtiana, a partir daquilo que é exposto na "Dialética do Esclarecimento" e da "Dialética negativa". ${ }^{4}$

O próprio modo como Adorno entende a aporia (enquanto limite estrutural do próprio pensar) nos dá pistas para correlacioná-la com o primado do objeto e com outra modalidade de pensamento, que se sustenta num procedimento bastante peculiar no qual a aporia ocupa posição fundamental. É então a partir dessas problemáticas, da relação com o objeto e da posição ocupada pela aporia no interior do pensamento frankfurtiano, que considero ser possível operar um reposicionamento ou uma ressignificação da condição aporética da crítica radical.

Este destino que a aporia assume - rejeição devido à crítica radical da razão - conduz ao caminho da correção ou da rejeição da crítica engendrada por Adorno e Horkheimer. Tomar a aporia como centro de nossa reflexão significa focalizar o ponto a partir do qual um importante interlocutor e herdeiro da primeira geração frankfurtiana afirma a inatualidade da primeira teoria crítica. Em outras palavras, tomo por tarefa refletir acerca do que julgo ser o ponto precípuo desta avaliação. Para Habermas, a aporia constitui-se como contradição insolúvel da primeira teoria crítica frankfurtiana, o que faria necessário o abandono ou a mudança radical de paradigma em seu interior. Porém, seria esta a única forma de lidar com a situação aporética da crítica da primeira geração frankfurtiana?

Tracei, então, para dar conta desta problemática, três formas de compreender a aporia: primeiro, enquanto horizonte da crítica radical da razão, tal como Habermas a compreende, isto é, aporia como produto do pensamento que deve ser superado; segundo, enquanto limite fundamental do próprio pensar, mais enfatizada por Adorno na "Dialética negativa"; terceiro, por fim, a aporia enquanto produtora de efeitos de análise social, ou seja,

4 Cumpre sublinhar que utilizo estas obras naquilo que toca o meu interesse neste artigo, a saber, de como a aporia aparece em alguns trechos. A complexidade dessas obras merecia estudo à parte. Dito isso, 0 que procurarei é realizar uma leitura pontual cuja pretensão passa longe de querer esgotar tais obras. 
enquanto força matriz do exercício do pensar crítico, como aquilo que força o pensamento a pensar, a partir da "Dialética do Esclarecimento".

\section{O reconhecimento da aporia como condição de possibilidade da crítica radical da razão}

Em determinado momento da "Dialética negativa", Adorno (2009, p. 133) afirma: "Os conceitos aporéticos da filosofia são as marcas daquilo que não é resolvido, não apenas pelo pensamento, mas objetivamente". A aporia é concebida, neste excerto, quase como uma imposição ao pensamento oriunda daquilo que é objetivo, externo. Salienta-se, deste modo, muito mais o fato de que há forças para além do pensamento que o condicionam, constrangem-no e limitam-no. Em resumo, pode-se equivaler aqui o objeto ao mundo externo não regulado pelo entendimento, caótico portanto.

Sabe-se, pelo menos desde a "Dialética do Esclarecimento", escrita cerca de vinte anos antes, como a produção de conhecimento racional passa por uma espécie de projeção cujo objetivo é dominar o objeto. Utilizando um exemplo da "Dialética do Esclarecimento" para elucidar este problema, enquanto a magia ainda é portadora de uma "substitutividade específica", perseguindo seus objetivos por meio da mimese, como no exemplo de rituais nos quais o feiticeiro torna-se semelhante aos demônios para assustá-los ou suavizá-los, a ciência moderna acaba com isso: "É a isso que ela dá fim. Nela não há nenhuma substitutividade específica: se ainda há animais sacrificiais, não há mais Deus. A substitutividade converte-se na fungibilidade universal" (Adorno; Horkheimer, 1985, p. 22).

Há, portanto, um distanciamento progressivo em relação ao objeto, na racionalidade esclarecida. O pensar do Esclarecimento se pauta em estruturas a priori de um sujeito cognoscente que dá inteligibilidade ao real: "As múltiplas afinidades entre os entes são recalcadas pela única relação entre o sujeito doador de sentido e o objeto sem sentido, entre o significado racional e o portador ocasional do significado" (Adorno; Horkheimer, 1985, p. 22). O que está em jogo é a primazia do sujeito que projeta sobre o real suas estruturas que lhe permitem compreendê-lo e dominá-lo para fins de autoconservação. "A distância do sujeito com relação ao objeto, que é o pressuposto da abstração, está fundada na distância em relação à coisa, que o senhor conquista através do dominado" (ibidem, p. 24).

Adorno e Horkheimer provavelmente têm em vista, ao realizar esta última afirmação, a situação emblemática que envolve Ulisses e o episódio das Sereias, situado no Canto 12 da "Odisseia" de Homero, na qual o protagonista 
se distancia do objeto, isto é, amarra-se ao mastro para não ceder ao feitiço das sereias, ao mesmo tempo que pode contemplar os belos sons, às custas da completa alienação dos remadores de seu barco em relação ao que se sucede naquele momento. Numa artimanha tipicamente freudiana, Adorno e Horkheimer mostram como o ato do sujeito cognoscente de projetar sobre o mundo suas categorias de entendimento está pautado num medo de que o objeto possa aniquilá-lo. A projeção pode transformar-se, assim, em paranoia.

Existe, pois, no Esclarecimento, uma dialética na qual o domínio da natureza converte-se em domínio dos próprios homens. O Esclarecimento é movido por certo delírio persecutório cuja ideia básica é a de que o objeto destruirá o sujeito, e isto o impulsiona a controlar, quantificar, manipular, dominar o real. Ocorre, assim, a transformação do pensamento em coisa, em instrumento, a conversão do pensamento em racionalidade instrumental que serve à finalidade de autoconservação do eu apartado do objeto. O medo é o fundamento da racionalidade: "o Esclarecimento tem perseguido sempre o objetivo de livrar os homens do medo e de investi-los na posição de senhores" (Adorno; Horkheimer, 1985, p. 17).

O projeto de livrar os homens do medo, portanto, acaba por se converter numa estrutura projetiva e paranoica que produz dominação: "a essência do Esclarecimento é a alternativa que torna inevitável a dominação" (Adorno; Horkheimer, 1985, p. 38). O objeto é sempre visto como algo a ser controlado, ainda que tal controle seja pago com o preço caro da submissão do sujeito, como ocorre na situação emblemática de Ulisses no episódio do Canto das Sereias.

Diante deste processo descrito de maneira catastrófica, Adorno e Horkheimer dão, pelo menos, duas pistas de um procedimento diferente da racionalidade instrumental: a primeira delas refere-se ao modo como eles mesmos realizam a leitura do Esclarecimento, isto é, mediante uma "teoria intransigente", ou seja, uma teoria que não contemporiza e nem cede ao seu procedimento de crítica. ${ }^{5}$ Afirmam, inclusive, que "uma verdadeira práxis revolucionária depende da intransigência da teoria, em face da inconsciência com que a sociedade deixa que o pensamento se enrijeça" (Adorno; Horkheimer,

5 Numa entrevista, publicada em 1969, Adorno (2003, p. 133) diz: “Diante da questão 'que fazer?' eu na realidade só consigo responder, na maioria dos casos, 'não sei'. Só posso tentar analisar de modo intransigente aquilo que é. Nisso me censuram: já que você exerce a crítica, então é também sua obrigação dizer como se deve fazer melhor as coisas. Mas é precisamente isso que eu considero um preconceito burguês. Verificou-se inúmeras vezes na história que precisamente obras que perseguiam propósitos puramente teóricos tenham modificado a consciência, e com isso também a realidade social". A propósito, é muito ilustrativo que o título dessa entrevista seja "A filosofia muda o mundo ao manter-se como teoria". 
1985 , p. 45). A segunda refere-se ao fato de que "o Esclarecimento pôs de lado a exigência clássica de pensar o pensamento" (ibidem, p. 33). Trata-se, então, além de sustentar uma teoria intransigente, de dirigir a reflexão crítica ao próprio pensamento.

$\mathrm{Na}$ "Dialética do Esclarecimento", este último gesto significa opor à racionalidade instrumental a reflexão crítica, isto é, tomar por objeto a própria racionalidade instrumental, entender sua gênese, as forças que a compõem, seus modos de efetivação em determinado tecido sócio-histórico etc. $\mathrm{O}$ movimento da crítica é o de pôr o impasse gerador da situação aporética para o interior do próprio procedimento de análise.

A determinação de pensar o pensamento sofre uma modificação substancial na "Dialética negativa", pois trata-se, a partir de então, de pensar contra o pensamento:

Se a dialética negativa reclama a autorreflexão do pensamento, então isso implica manifestamente que o pensamento também precisa, para ser verdadeiro, hoje em todo caso, pensar contra si mesmo. Se ele não se mede pelo que há de mais exterior e que escapa ao conceito, então ele é de antemão marcado pela música de acompanhamento com a qual os SS adoravam encobrir os gritos de suas vítimas (Adorno, 2009, p. 302).

A intransigência da teoria e a atitude de pensar o pensamento são boas ferramentas, mas não bastam. É preciso que o pensamento tenha uma outra relação com o objeto. A filosofia comporta um "esforço de ir do conceito para além do conceito" (Adorno, 2009, p. 22). A aporia, como sublinhei anteriormente, é a marca do que está irresoluto não só no pensamento, mas objetivamente.

A partir daqui, convém dar mais um passo na direção do reconhecimento da aporia não enquanto obstáculo insolúvel ou horizonte inultrapassável: é o objeto que põe uma tarefa ao pensamento, e isto é feito por tal reconhecimento de sua inevitabilidade. Contudo, este objeto não é apenas o lado de fora de todo pensamento, mas aquilo que está historicamente determinado.

O fundamento histórico da aporia é o fato de na Alemanha, a revolução contra os fascistas ter fracassado ou, muito mais, o fato de não ter havido em 1944 nenhum movimento revolucionário de massas (Adorno, 2009, p. 239). ${ }^{6}$

6 Nesta passagem específica, devo notar que o problema que Adorno está enfrentando diz respeito à condenação dos fascistas que fugiram e se mantiveram escondido por duas décadas. Reflete acerca do que deve ser feito com eles, condená-los ou deixá-los livres - sobre isso o filme "O Lavador de Almas" (The Last Hangman, 2005, do diretor Adrian Shergold) é bastante ilustrativo. Ademais, em outra ocasião, Adorno (2011, p. 34) sustenta, no mesmo sentido, que "o movimento alemão de resistência ao nazismo permaneceu sem uma base de massas, base que dificilmente seria gerada com a derrota como se fosse 
Conectando esta frase com aquela outra sobre a irresolutividade objetiva, podemos afirmar que a aporia praticamente força o pensamento a pôr questões que talvez ele não seja capaz de responder dentro de seu sistema lógico: "a filosofia quer mergulhar muito mais literalmente no que lhe é heterogêneo, sem o reduzir a categorias pré-fabricadas" (Adorno, 2009, p. 19).

É possível compreender a aporia, para além do limite estrutural do pensar, como aquilo a partir do qual a crítica impõe suas próprias exigências de reflexão e, assim, constitui o núcleo potente de produção de efeitos de análise social no procedimento crítico. Neste sentido, ela pode ser compreendida como $a$ condição de possibilidade da crítica frankfurtiana. Tomemos como exemplo a aporia com a qual a "Dialética do Esclarecimento" se vê emaranhada, para lê-la de acordo com o que propus.

Em primeiro lugar, demonstro como a crítica exposta na "Dialética do Esclarecimento" é forçada a existir por uma contradição concreta e histórica: a humanidade, em vez de entrar num estado verdadeiramente humano, ou seja, de uma autonomia consolidada pelo uso da razão capaz de produzir uma sociedade melhor, no sentido de mais justa, igualitária e fraterna, afundou-se em uma nova espécie de barbárie. Aqui, a aporia é compreendida na ordem histórica e objetiva: há uma situação aporética, ou seja, uma desordem lógica ou mesmo uma antinomia entre projeto emancipatório do Esclarecimento e a situação de barbárie ocasionada especificamente (mas não somente) pelo fascismo alemão.

A exigência de pensar o pensamento faz com que a situação aporética seja considerada no procedimento crítico enquanto objeto a partir do qual o pensamento tentará buscar compreensão: "A aporia com que defrontamos em nosso trabalho revela-se como primeiro objeto a investigar: a autodestruição do Esclarecimento" (Adorno; Horkheimer, 1985, p. 38). Este objeto se torna alvo de investigação para o pensamento. Ele é uma exigência do objeto, no sentido de ser um acontecimento histórico que provoca o pensamento a pensar: como um projeto de autonomia desembocou num mundo heterônomo?

Se há uma exigência externa ao pensamento, o próprio procedimento utilizado é fronteiriço no que se refere ao que é conceitualmente o Esclarecimento e a formas de dominação presentes na sociedade:

por um toque de mágica". Destacamos esta frase no sentido de mostrar como a aporia exerce sobre o pensamento uma força primeva, como algo que força o pensamento a pensar, devido à sua inscrição na exterioridade, na história. Se no terreno histórico a negatividade se rompeu (o elemento negatório capaz de operar a transformação radical da sociedade se encontra ausente), dentro da teoria é a própria possibilidade de superação dialética que se encontra em suspenso. 
Acreditamos ter reconhecido com a mesma clareza que o próprio conceito desse pensamento, tanto quanto as formas históricas concretas, as instituições da sociedade com as quais está entrelaçado, contém o germe para a regressão que hoje tem lugar por toda parte. Se o Esclarecimento não acolhe dentro de si a reflexão sobre esse elemento regressivo, ele está selando seu próprio destino (Adorno; Horkheimer, 1985, p. 13).

Não se trata somente de pensar o modo como o conceito de Esclarecimento contém germes de regressão, mas também a figura que este assume na realidade efetiva. Os conceitos devem, portanto, "ser compreendidos não apenas como histórico-culturais, mas como reais" (Adorno; Horkheimer, 1985, p. 13). Ou seja, trata-se de investigar como a racionalidade se entrelaça com as instituições sociais. Em outras palavras, o que está em questão são as formas concretas nas quais a racionalidade entra em funcionamento. Não é por acaso que o primeiro estudo, "O conceito de Esclarecimento", "fundamento teórico dos seguintes, procura tornar mais inteligível o entrelaçamento da racionalidade e da realidade social" (Adorno; Horkheimer, 1985, p. 15).

Deste modo, esquematicamente posso dizer que, concebida desta maneira, a situação aporética força o pensamento a pensar por meio da eleição de um objeto em si contraditório e contra a lógica: a autodestruição do Esclarecimento. Este objeto, por sua vez, obriga a produção de um procedimento de reflexão que afirma a prioridade não do conceito, mas de sua conexão com uma realidade historicamente determinada; trata-se de uma racionalidade que não é abstrata, mas efetiva, que se entrelaça em instituições sociais: uma razão impura (McCarthy, 1994). O procedimento, por fim, contribui para a produção de um diagnóstico do presente, que permite a leitura de uma conjuntura histórica e politicamente determinada.

A aporia ocupa, assim, papel fundamental no processo de montagem da crítica radical da razão da primeira geração frankfurtiana. Esta montagem passa não pelo jugo da lógica racional, mas pelo crivo de um problema historicamente preciso. A razão surge como objeto da crítica por uma exigência externa ao pensamento. Ela é colocada em suspenso, sub judice, porque ela própria, mediante o Esclarecimento, ensejou uma situação aporética histórica devido aos modos de dominação que acabaram por convertê-la em seu contrário.

Por exemplo, se a cultura poderia ser pensada como construção de um homem autônomo, a Indústria Cultural acabou por produzir, ao contrário, indivíduos alienados, massificados; se a Razão poderia ser compreendida como meio pelo qual o homem alcançaria a maioridade, utilizando-a para se constituir enquanto livre, por intermédio de uma vontade racional autônoma, a 
racionalidade instrumental acaba por converter este processo em heteronomia e o sujeito se vê cada vez mais subjugado ao cálculo, aos fins.

Talvez tenha sido por estes fatores - a eleição de um problema por imposição de uma realidade histórica precisa, a criação de novo procedimento de análise que põe a razão como objeto de investigação crítica em sua ligação com a realidade efetiva e a produção de um diagnóstico do presente - que Adorno, embora consciente da existência da aporia no sentido que Habermas a entende, tenha preferido sustentar suas análises mantendo a condição aporética de seu pensamento como virtude de seu procedimento.

Portanto, reposicionar a aporia, entendendo-a não como consequência da análise radical, isto é, como chegada a um beco sem saída, mas sim como condição de possibilidade, permite-me deslocar a questão de por que Adorno não cedeu, permaneceu intransigente em relação a isso, para o como ele foi capaz de não ceder. Posso dizer agora, se o que expus estiver correto, como: por meio da exigência do pensamento de pensar algo radicalmente outro.

Adorno e Horkheimer compreendem como a aporia não é algo a ser extirpado do pensamento, mas algo a ser mantido, sustentado a fim de que seja possível a produção de efeitos de análise em direção ao diagnóstico do presente. Deste modo, o destino da aporia não é a lata de lixo da história do pensamento crítico nem aquilo que justificaria uma mudança de paradigma, mas o lugar heterogêneo, do não idêntico, a partir do qual o pensamento é forçado a pensar.

Aliás, foi esta posição da aporia enquanto aquilo que força o pensamento a pensar que introduziu, em certa medida, uma mudança de consequências inéditas para a teoria social, pois, pela primeira vez, de uma perspectiva crítica e emancipatória, a tradição do Esclarecimento como tal foi posta em questão: a barbárie, materializada histórica e politicamente no fascismo, não foi um monstro alheio ou um tropeço do Espírito Absoluto, mas sim um legítimo descendente do próprio Esclarecimento (Kurz, 1997).

Para concluir este ponto acerca da posição da aporia, lembremos como, na "Dialética negativa", Adorno reflete sobre o que chama de primado do objeto no processo de pensamento:

Ele recebe seu impulso da coisa. Diferenciado é aquele que, na coisa e em seu conceito, ainda consegue distinguir o mais ínfimo que escapa ao conceito; somente a diferencialidade alcança o mais ínfimo. Em seu postulado, ou seja, no postulado da faculdade da experiência do objeto - e a diferencialidade é a sua experiência transformada em forma de reação subjetiva -, o momento mimético do conhecimento, o momento da afinidade eletiva entre aquele que conhece e aquilo que é conhecido, encontra refúgio. No interior do processo conjunto do Esclarecimento, esse momento vai se desfazendo pouco a pouco (Adorno, 2009, p. 46). 
Para Adorno, o exterior tem posição privilegiada no processo de pensamento. A ponto de o próprio processo de pensamento ser secundário ao objeto: "cabe à filosofia pensar aquilo que é diverso do pensamento e que o transforma pela primeira vez em pensamento" (Adorno, 2009, p. 165). Este pensamento, mediante a defesa do primado do objeto, acaba por manter a irredutibilidade do não idêntico, entendendo-o não como aquilo que deve ceder às categorias lógicas do pensamento, mas como algo que propulsiona 0 próprio pensamento a pensar, tanto no nível fundamental quanto na ordem da crítica social.

É por meio desta outra modalidade de relação entre crítica da razão e análise social, que podemos entender de que maneira a aporia se inscreve no pensamento da primeira geração, isto é, de modo metodológico, como algo cuja função é permitir o exercício da crítica:

De certo modo, Adorno faz dessa lógica aporética método: as tensões e ambiguidades herdadas pelo marxismo e pela teoria crítica da sociedade constituem o único elemento em que se pode pensar, ou seja, pensar no "estado falso" é pensar no interior das aporias inevitáveis do projeto moderno. Mais ainda, para Adorno, o objeto da teoria é justamente a inevitabilidade das aporias (Nobre, 1998, p. 183).

A aporia é uma contradição lógica de origem histórica que se impõe ao pensamento devido à sua tarefa de produzir efeitos de análise social. É neste sentido que a concebemos enquanto potência da crítica e como conceito que nos torna possível refletir acerca da atualidade da análise social da primeira geração frankfurtiana.

\section{Vitalidade e atualidade da primeira geração frankfurtiana}

Ao longo deste artigo, busquei refletir acerca da visão de que devido às deficiências analíticas oriundas do próprio procedimento crítico frankfurtiano seriam inevitáveis tanto a mudança de paradigma na teoria crítica quanto a recusa da crítica radical da razão. Com relação a isso, Zamora (2009) constata o modo pelo qual se consolidou certa visão baseada no fato de que o pensamento de Adorno e da primeira geração como um todo estariam superados, suas aporias e becos sem saída haviam sido postos à baila pela "nova geração" de frankfurtianos.

A corrente elétrica que anima o presente artigo refere-se principalmente a uma problematização deste empreendimento de despotencialização da crítica radical da primeira geração frankfurtiana, onde ocorre algo que se pode 
chamar de desradicalização de uma geração intelectual. ${ }^{7}$ Deste modo, ao analisar a crítica de Habermas chego à conclusão de que somos conduzidos, na verdade, ao núcleo de força da crítica social de Adorno e Horkheimer.

As situações aporéticas nas quais o pensamento social da primeira geração da Escola de Frankfurt encontra-se enredado paradoxalmente constituem a potência do procedimento crítico. No que se refere a Habermas, defendi que a crítica não se enreda na aporia, mas sim se inicia a partir dela, sendo ela mesma a condição de efetividade da crítica radical. Assim, em vez de aporia ser algo para o qual a crítica se vê conduzida, é ela própria o ponto de partida que torna possível a crítica radical da razão como ferramenta de análise social.

Desta maneira, Adorno e Horkheimer não realizam uma crítica do poder, ou seja, uma análise cujo objeto é determinada forma histórica de poder, como no caso do fascismo. Isto acarretaria afirmar, por exemplo, como faz Honneth (2009), importante membro da chamada terceira geração frankfurtiana, que a derrocada do fascismo também levou à obsolescência da leitura adorniana da modernidade. De modo diverso, a crítica tem como condicionantes a política e a história, que põem para o pensamento a obrigatoriedade de pensar o novo.

O que Adorno e Horkheimer realizam é o exercício da potência da crítica, a saber, o movimento pelo qual o pensamento busca, no encontro com aquilo que lhe é exterior (histórico e político) produzir novos modos de pensar que possam conduzir outras formas de viver. Este pensamento deve à aporia não a sua limitação e sim a sua vitalidade.

O atual rearranjo social, oriundo das transformações ocorridas no interior do processo de produção capitalista na década de 1970 (Jameson, 2002; Harvey, 1993), confirma não só a vitalidade teórico-analítica da primeira geração frankfurtiana, mas também a materialidade da barbárie, um de seus objetos principais de análise. Autores próximos à teoria crítica, como Kurz (1992) e Postone (1993), apontam para o esgotamento desta forma social por meio da crise do trabalho e pela produção de uma massa supérflua para além do modo de produção vigente, no sentido de serem populações incapazes de realizar a mediação social básica do capitalismo: comprar e vender. Tratase do chamado desemprego estrutural, isto é, não mais cíclico e não mais composto por aquele exército industrial de reserva pronto a retornar ao processo de trabalho (Mészáros, 2011).

Ao contrário, a consequência da chamada terceira revolução industrial é a tendência de supressão do trabalho vivo pelo trabalho morto (as máquinas). 
O resultado disso é um desemprego cada vez mais crescente e insolúvel. ${ }^{8} \mathrm{~A}$ barbárie é uma das chaves compreensivas para se pensar o nosso tempo, na medida em que ela é resultado da incapacidade de se criar outra destinação das bases objetivas de produção social (Menegat, 2012).

Do mesmo modo como a primeira geração frankfurtiana viveu numa sociedade na qual o recurso à barbárie foi plenamente desenvolvido em prol do projeto totalitário de sociedade, para nós do início do século XXI a barbarização das relações sociais continua não sendo algo da ordem do acidente ou do incoerente: ela é o produto mesmo desta forma social e, na atualidade, uma possibilidade de realização histórica, uma vez que, por exemplo, as formas fetichizadas de anticapitalismo, por meio do antissemitismo contemporâneo (Postone, 1986), a nossa guerra civil brasileira declarada e o boom da criminalidade no capitalismo tardio (Wacquant, 2003) ganham força nos grandes embates sociais contemporâneos. Portanto, a barbárie continua sendo um eixo de interpretação crítica da atual quadratura da sociedade burguesa, apontando para o seu esgotamento civilizatório (Menegat, 2012, p. 19).

Isto posto, a defesa da radicalidade da primeira geração frankfurtiana tem seu momento de verdade na atual conjuntura social, histórica e política. O rearranjo sociopolítico hodierno gira em torno também do desmonte do Estado de bem-estar social, impulsionado pelo chamado neoliberalismo, fenômeno que nem mesmo a teoria crítica considerou possível (Türcke, 2005). Não obstante, diante da mudança do quadro social nas últimas décadas, a primeira geração frankfurtiana nos fornece instrumentos analíticos capazes de dar conta de nosso tempo marcado pela dinâmica de regressão histórica.

Mais uma vez, o sujeito $d a$ história não se faz presente para operar a necessária transformação do tempo presente, a teoria então se encontra numa situação aporética, pois o suporte social de sua realização não está formado, embora a necessidade de superação social seja urgente. De modo adorniano, se a filosofia se mantém viva porque perdeu o instante de sua realização, cabe manter a tensão dialética. É preciso sublinhar que as formas de resistência não são atributos de um sujeito pré-dado, dedutível de sua posição no processo

8 Isto pode ser verificado nos altos índices de desemprego, por exemplo: 17,5\% em Portugal, 26,7\% na Espanha, 27,2\% na Grécia. Cf. <http://www.dinheirovivo.pt/Graficos/Detalhe/CIECO150428.html>. Aqui no Brasil, o contorno desta crise tem como consequência a proliferação daquilo que Antunes (1995) chama de classe-que-vive-do-trabalho, isto é, os setores sociais para além da fábrica, que dependem da venda de sua força de trabalho para viver. Contudo, é preciso notar aqui também aquelas massas supérfluas jogadas para fora do processo produtivo (incapazes de realizar a venda de sua própria força de trabalho) e que precisam ser dimensionadas na crítica social. 
de produção, por exemplo. A história não cessa de produzir momentos de resistência nos quais se forjam sujeitos que empreendem ações contestatórias, como bem apontou Marcuse ao longo de todo seu percurso intelectual.

Deste modo, a condição de existência, em determinados contextos, só encontra expressão na revolta. É isso que define a constituição do sujeito $n a$ história, capaz de lutar e empreender ações emancipatórias. Assim, como nos legou a primeira geração frankfurtiana, cabe fazer dessa atual condição aporética da crítica não o beco sem saída, mas sim o princípio a partir do qual se deve formular adequadamente o problema de nossa época, a saber, a superação da forma social mediada pelo valor: o capitalismo. Aqui, a crítica da teoria é um momento necessário em direção à crítica do real.

\section{Referências}

ABBAGnANO, N. "Dicionário de Filosofia". São Paulo: Martins Fontes, 2012. ADORNO, T. "A filosofia muda o mundo ao manter-se como teoria". Lua Nova, Nr. 60, pp. 131-138, 2003.

. "A Dialética Negativa". Rio de Janeiro: Jorge Zahar, 2009.

. "O que significa elaborar o passado". In: Educação e emancipação.

São Paulo: Paz e Terra, 2011.

ADORNO, T.; HORKHEIMER, M. "A Dialética do Esclarecimento: fragmentos filosóficos". Rio de Janeiro: Jorge Zahar, 1985.

ANTUNES, R. “Adeus ao trabalho?”. São Paulo: Cortez, 1995.

BENJAMIN, W. "Teses sobre filosofia da história”. In: W. Benjamin. Sociologia. 2a ed. São Paulo: Ática, 1991. pp. 153-164.

BLANK, J. "Manuel Castells, as forças produtivas e a des-radicalização de uma geração intelectual". 207 f. Tese (Doutorado em Serviço Social) - Universidade Federal do Rio de Janeiro, 2010.

CHAUÍ, M. "Introdução à história da filosofia: dos pré-socráticos a Aristóteles: volume 1". São Paulo: Companhia das Letras, 2002.

CUSSET, Y.; HABER, S. "Le vocabulaire de l'ecole de Francfort". Paris: Ellipses Édition Marketing S.A., 2002.

HABERMAS, J. "Concepções de modernidade. Um olhar retrospectivo sobre duas tradições". In: A constelação pós-nacional: ensaios políticos. São Paulo: Littera Mundi, 2001. pp. 167-198.

2000.

. "O discurso filosófico da modernidade". São Paulo: Martins Fontes, . "Pensamento pós-metafísico: estudos filosóficos". Rio de Janeiro:

Tempo Brasileiro, 1990.

. "Teoría de la acción comunicativa". Madrid: Trotta, 2010. “Verdade e justificação: ensaios filosóficos”. São Paulo: Loyola, 2004. 
HARVEY, D. “A condição pós-moderna”. São Paulo: Loyola, 1993.

HOMERO. "Odisseia". Porto Alegre: L\&PM, 2009. Vol. 2: "Regresso".

HONNETH, A. "Crítica del poder: fases en la reflexión de una teoria crítica de la sociedad". Madrid: Machado Libros, 2009.

. "Michel Foucault e a Escola de Frankfurt: reflexões a partir da obra

Crítica do Poder". Trans/Form/Ação, Marília, Vol. 35, Nr. 3, pp. 157-188, set./dez., 2012. HOUAISS, A.; VILLAR, M. S. "Grande Dicionário Houaiss de Língua Portuguesa". Rio de Janeiro: Objetiva, 2001.

JAPIASSU, H.; MARCONDES, D. “Dicionário Básico de Filosofia”. Rio de Janeiro: Jorge Zahar, 2006.

JAY, M. "Fugas urbanas: el Instituto de Investigación Social entre Frankfurt y Nueva York". In: Campos de fuerzas: entre la historia intelectual y la crítica cultural. Buenos Aires: Paidós, 2003a.

. "El debate sobre la contradicción performativa: Habermas versus los posestructuralistas". In: Campos de fuerzas: entre la historia intelectual y la crítica cultural. Buenos Aires: Paidós, 2003b.

JAMESON, F. "Pós-modernismo: a lógica cultural do capitalismo tardio". São Paulo: Ática, 2002.

KIERKEGAARD, S. “Migalhas Filosóficas”. Petrópolis: Vozes, 1995.

KURZ, R. "Até a última gota". Folha de S.Paulo, 24 ago. 1997, caderno Mais!.

KURZ, R. "O colapso da modernização: da derrocada do socialismo de caserna à crise da economia mundial". Rio de Janeiro: Paz e Terra, 1992.

MCCARTHY, T. "The Critique of Impure Reason: Foucault and The Frankfurt School". In: M. Kelly (org.). Critique and power: recasting the Foucault/Habermas debate. MIT Press, 1994.

MENEGAT, M. "Estudos sobre ruínas". Rio de Janeiro: Revan, 2012.

MÉSZÁROS, I. "Para além do capital: rumo a uma teoria da transição". São Paulo: Boitempo, 2011.

NOBRE, M. "A dialética negativa de Theodor W. Adorno: A ontologia do estado falso". São Paulo: Iluminuras, 1998.

POSTONE, M. “Anti-Semitism and National Socialism". In: A. Rabinbach \& J. Zipes (ed.). Germans and Jews since the Holocaust. New York: Holmes and Meier, 1986.

POSTONE, M. "Time, labor and social domination: a reinterpretation of Marx's critical theory". Cambridge University Press, 1993.

REPA, L. "Contradição performativa". In: M. Nobre (org.). Curso livre de teoria crítica. São Paulo: Papirus, 2008.

ROUANET, S. P. "Razão negativa e razão comunicativa”. In: As razões do iluminismo. São Paulo: Cia das Letras, 1987.

SLATER, P. "Origem e significado da Escola de Frankfurt". Rio de Janeiro: Zahar, 1978.

SOARES, J. C.; EWALD, A. P. "Escola de Frankfurt: 'o elogio da sombra'”. Estud. pesqui. psicol. [online]. Vol. 11, n. 1, pp. 9-22, 2011. Disponível em: http://www. 
revispsi.uerj.br/v11n1/artigos/pdf/v11n1a02.pdf. Acessado em: 05 de dezembro de 2011.

TÜRCKE, C. “'Informal' segundo Adorno”. In: R. Duarte (org.). Theoria Aesthetica - em comemoração ao centenário de Adorno. Porto Alegre: Escritos, 2005.

WACQUANT, L. "Punir os pobres: a Administração da Miséria nos Estados Unidos". Rio de Janeiro: REVAN, 2003.

ZAMORA, J. A. "Actualidade de la teoría crítica". Constelaciones - Revista de Teoría Crítica, Vol. 1, pp. 176-182, 2009. 